\title{
Alterações Morfológicas de Plântulas de Trigo, Azevém e NABo QuANDo EM Competição nos Estádios Iniciais DE Crescimento $^{1}$
}

\author{
Morphological Alterations in Wheat, Italian Ryegrass and Radish Seedlings When in Competition \\ in at the Initial Stages of Growth
}

LAMEGO, F.P. ${ }^{2}$, REINEHR, M. ${ }^{3}$, CUTTI, L. ${ }^{4}$, AGUIAR, A.C.M. ${ }^{4}$, RIGON, C.A.G. ${ }^{4}$ e PAGLIARINI, I.B. ${ }^{4}$

\begin{abstract}
RESUMO - Alterações na qualidade da radiação luminosa causadas pela presença de "plantas vizinhas" podem desencadear uma série de respostas morfológicas das espécies de interesse. O objetivo deste estudo foi avaliar o efeito do crescimento de plântulas de trigo, azevém (Lolium multiflorum) e nabo (Raphanus sativus), em competição nos estádios iniciais de desenvolvimento. Foram realizados três experimentos em casa de vegetação, em delineamento de blocos casualizados com quatro repetições. No primeiro experimento, avaliou-se o crescimento do trigo (cv. Fundacep Cristalino) em competição com azevém, nabo ou trigo (cv. BRS Guamirim). No segundo, a espécie estudada foi o azevém sob competição com plantas de trigo (cv. Fundacep Cristalino) e nabo e, no terceiro, o nabo em competição inicial com plantas de trigo (cv. Fundacep Cristalino) e azevém. Em todos os experimentos, foi adicionado tratamento em que a planta principal cresceu livre da interferência inicial. Aos 15 dias após a semeadura, as plantas foram submetidas às avaliações de estatura de planta, comprimento do sistema radicular, diâmetro de caule e contagem do número de raízes emitidas. A estatura de planta do trigo foi $36 \%$ maior quando cultivado em competição com o azevém. O azevém apresentou incremento de $172 \%$ na MSPA quando competindo com o nabo, em comparação à testemunha sem competidores. Conclui-se que a competição inicial com base na radiação luminosa, uma vez que não houve limitação de água e nutrientes, altera as características morfofisiológicas de plântulas de trigo cv. Fundacep Cristalino, azevém e nabo, independentemente da espécie competidora em questão.
\end{abstract}

Palavras-chave: radiação solar, Triticum aestivum, Lolium multiflorum, Raphanus sativus, planta competidora.

\begin{abstract}
Alterations in the quality of light radiation caused by the presence of "neighbor plants" can trigger a series of morphology results of species in focus. The objective of this study was to assess the effect of the growth of wheat, Italian ryegrass (Lolium multiflorum) and radish (Raphanus sativus) seedlings, in competition at the initial stages of development. Three experiments were conducted in greenhouse, in a complete randomized block design, with four replications. On the first experiment, wheat growth (cv. Fundacep Cristalino) was assessed in competition with Italian ryegrass, radish or wheat ( $c v$. BRS Guamirim). On the second, the species studied was Italian ryegrass under competition with wheat plants (cv. Fundacep Cristalino) and radish and on the third one, radish with initial competition with wheat plants ( $c v$. Fundacep Cristalino) and Italian ryegrass. In all experiments, an additional treatment where the main plant growths free of initial interference was included. At 15 days after seeding, plants were submitted to evaluation of plant height, root system length, stem diameter and the number of developed roots was recorded. Plant height of wheat (cv. Fundacep Cristalino) was 36\% higher when cultivated in competition with Italian ryegrass. Italian ryegrass showed an increase of $172 \%$ in MSPA when competing with radish when compared to untreated check without competitors. It was concluded that initial competition based on the light radiation, once there was no limitation of water and nutrients, affect the morphophisiological characteristics of wheat (cv. Fundacep Cristalino), Italian ryegrass and radish seedlings, regardless of the competitor species in focus.
\end{abstract}

Keywords: solar radiation, Triticum aestivum, Lolium multiflorum, Raphanus sativus, competitor plant.

Recebido para publicação em 26.11.2014 e aprovado em 14.12.2014.

Pesquisadora da Embrapa Pecuária Sul, Bagé-RS, <fabiane.lamego@embrapa.br>; ${ }^{3}$ Mestranda do PPGAAA - Programa de PósGraduação em Agronomia: Agricultura e Ambiente/Universidade Federal de Santa Maria (UFSM), Campus Frederico WestphalenRS, Brasil, ${ }^{4}$ Graduandos do Curso de Agronomia da UFSM, Campus Frederico Westphalen-RS.

Planta Daninha, Viçosa-MG, v. 33, n. 1, p. 13-22, 2015 


\section{INTRODUÇÃO}

Plantas que ocorrem em um mesmo nicho ecológico estão sujeitas a diversas interações, diretas e indiretas. Entre as interações diretas, a competição por radiação solar é uma das mais importantes, por ser "matéria-prima" para a atividade metabólica das plantas (Zanine \& Santos, 2004). Em campo, quando a adubação dos cultivos for realizada corretamente e havendo água disponivel, as plantas competem pela radiação luminosa, que passa a ser o elemento mais limitado no meio (Zanine \& Santos, 2004).

As plântulas têm capacidade de regular a distribuição dos fotoassimilados de acordo com a qualidade de radiação interceptada no início do seu desenvolvimento (Taiz \& Zeiger, 2004). A presença de plantas "vizinhas" altera o crescimento da parte aérea, como forma de melhorar a eficiência na captura da radiação luminosa e evitar o sombreamento.

As respostas das plantas ao estresse luminoso ocasionado pela competição são múltiplas, sendo uma das principais caracterizada por alterações no sistema radicular e redução da área de exploração, que afetam diretamente as taxas de absorção de água e nutrientes (Taiz \& Zeiger, 2004). Para o trigo, a competição por luz pode reduzir o número de afilhos (Almeida \& Mundstock, 2001) e pode estar relacionada com a redução na área foliar da planta e, consequentemente, dos fotoassimilados (Valério et al., 2009).

As alterações morfológicas e aquelas que ocorrem em detrimento da competição pela radiação luminosa na fase inicial de desenvolvimento das culturas foram denominadas de "Síndrome do Escape do Sombreamento" (Stoller \& Woolley, 1985; Ballaré et al., 1987, 1990) ou "Inicialismo" (Vidal et al., 2012). As plantas apresentam desequilíbrio energético, o qual resulta em alongamento e redução do diâmetro de caule e do acúmulo de biomassa na parte aérea e radicular (Afifi \& Swanton, 2012), bem como em mudança na orientação das folhas (Rajcan \& Swanton, 2004). No entanto, Ballaré \& Casal (2000) enfatizam que os efeitos dos sinais de luz percebidos por fotorreceptores (fitocromos) podem ser diferentes para a cultura e as plantas daninhas competidoras. Isso se explica pelo fato de a planta passar a investir sua energia no crescimento da parte aérea e do sistema radicular, apresentando, consequentemente, redução sensivel em seu crescimento e desenvolvimento (Vidal \& Merotto Jr., 2010), e uma das principais alterações morfológicas observadas é o estiolamento do caule das plantas (Merotto Jr. et al., 2002, 2009). Esse sintoma pode ser compreendido como um mecanismo de escape e busca pela radiação luminosa de qualidade e quantidade suficiente para restabelecer o equilíbrio energético da planta.

A hipótese do presente estudo está alicerçada na redistribuição energética e no desbalanço físiológico e morfológico das plantas que competem por radiação luminosa ainda em estádios iniciais de crescimento, acreditando que aquelas que venham a emergir em ambiente com possivel sombreamento sejam menos competitivas que plantas cuja emergência ocorra em ambiente livre de competição. Desse modo, o objetivo do presente estudo foi avaliar o efeito sobre o crescimento de plântulas de trigo, de azevém (Lolium multiflorum) ou de nabo (Raphanus sativus), quando emergidas na presença de plantas vizinhas competidoras.

\section{MATERIAL E MÉTODOS}

Foram realizados três experimentos em casa de vegetação do Departamento de Ciências Agronômicas e Ambientais da Universidade Federal de Santa Maria-UFSM, Campus de Frederico Westphalen-RS, no período de maio a junho de 2013. O delineamento experimental adotado foi inteiramente casualizado (DIC) com quatro repetições. As unidades experimentais foram vasos plásticos com capacidade de 6 L, cujo centro foi ocupado por copo plástico com capacidade de $500 \mathrm{~mL}$, ambos preenchidos com substrato agrícola (Tecnomax ${ }^{\circledR}$ ).

Para cada experimento, os tratamentos foram constituídos de uma planta principal e uma planta competidora: para o experimento 1 , a planta principal foi o trigo (cv. Fundacep Cristalino), além das competidoras azevém, nabo ou trigo (cv. BRS Guamirim) e da testemunha (trigo isolado, sem planta competidora); para o experimento 2, a planta principal foi o azevém e as competidoras trigo (cv. Fundacep 
Cristalino) ou nabo e a testemunha (sem planta competidora); e, para o experimento 3 , o nabo foi a planta principal e as competidoras o trigo (cv. Fundacep Cristalino) ou o azevém, além da testemunha (sem planta competidora).

Para simular a competição inicial pela radiação luminosa, foram semeados como plantas competidoras os cultivares de trigo, azevém ou nabo no entorno do vaso plástico, de acordo com o tratamento em questão (Tabela 1). Em razão de apresentar lento desenvolvimento inicial, o azevém, quando planta competidora, foi semeado 14 dias antes da implantação da planta do centro do vaso, sendo o trigo e o nabo instalados sete dias antes. O fornecimento de água durante o período inicial do experimento foi limitado à área do vaso onde foram semeadas as plantas responsáveis pela competição, uma vez que os copos não apresentavam orifícios de drenagem, visando ao isolamento de possivel competição radicular por água e nutrientes entre as plantas.

No centro do vaso plástico foi acondicionado um copo plástico de $500 \mathrm{~mL}(12,6 \times 9 \mathrm{~cm}$ - altura x diâmetro do copo), onde foram semeadas posteriormente sementes de trigo, cv. Fundacep Cristalino, ou as espécies daninhas azevém ou nabo, conforme a planta competidora em questão. Antes de serem transplantadas aos copos plásticos, sementes foram pré-germinadas em estufa BOD à temperatura constante de $20{ }^{\circ} \mathrm{C}$ e fotoperiodo de $12 / 12 \mathrm{~h} \mathrm{dia/noite,} \mathrm{permanecendo} \mathrm{embe-}$ bidas em água destilada por 24 horas. Antes da emissão da radícula, as sementes foram transplantadas para os copos plásticos, a cerca de $2 \mathrm{~cm}$ de profundidade, e cobertas com substrato, onde permaneceram até os 15 dias após a semeadura (DAS) (Figura 1). Estabeleceu-se uma plântula por copo, sendo semeada apenas uma semente pré-germinada por copo.

Por ocasião dos 15 DAS, nos copos plásticos, foi feita a coleta das plantas, as quais foram submetidas às seguintes avaliações: determinação da estatura da planta $(\mathrm{cm})$, tomando-se por base o colo da planta até o ápice da folha mais desenvolvida; comprimento do sistema radicular $(\mathrm{cm})$, medido do coleto da plântula até a coifa da raiz; diâmetro de caule $(\mathrm{cm})$, medido no coleto da plântula com paquímetro; e contagem do número de raízes emitidas. Posteriormente, as plantas coletadas foram acondicionadas em sacos de papel e depositadas em estufa, sendo mantidas sob temperatura constante de cerca de $60{ }^{\circ} \mathrm{C}$ até que atingissem peso constante, quando foram pesadas com auxílio de balança de precisão, para determinação da massa seca da parte aérea (MSPA).

Os dados coletados foram submetidos à análise de homocedasticidade, onde foi realizada a verificação da homogeneidade da variância, utilizando-se os testes de Bartlett,

Tabela 1 - Tratamentos utilizados na condução do experimento de competição inicial por radiação luminosa. UFSM, Campus Frederico Westphalen-RS, 2013

\begin{tabular}{|l|l|l|}
\hline \multicolumn{1}{|c|}{ Planta } & \multicolumn{1}{c|}{ Competidor } \\
\hline \multicolumn{3}{|c|}{ Experimento I } \\
\hline 1 & Trigo (cv. Fundacep Cristalino) & Azevém \\
\hline 2 & Trigo (cv. Fundacep Cristalino) & Nabo \\
\hline 3 & Trigo (cv. Fundacep Cristalino) & Trigo (cv. BRS Guamirim) \\
\hline 4 & Trigo (cv. Fundacep Cristalino) & Testemunha (sem competição) \\
\hline \multicolumn{3}{|l|}{ Experimento II } \\
\hline 1 & Azevém & \multicolumn{2}{|l|}{ Trigo (cv. Fundacep Cristalino) } \\
\hline 2 & Azevém & Nabo \\
\hline 3 & Azevém & Testemunha (sem competição) \\
\hline \multicolumn{3}{|l|}{ Experimento III } \\
\hline 1 & Nabo & Trigo (cv. Fundacep Cristalino) \\
\hline 2 & Nabo & Azevém \\
\hline 3 & Nabo & Testemunha (sem competição) \\
\hline
\end{tabular}




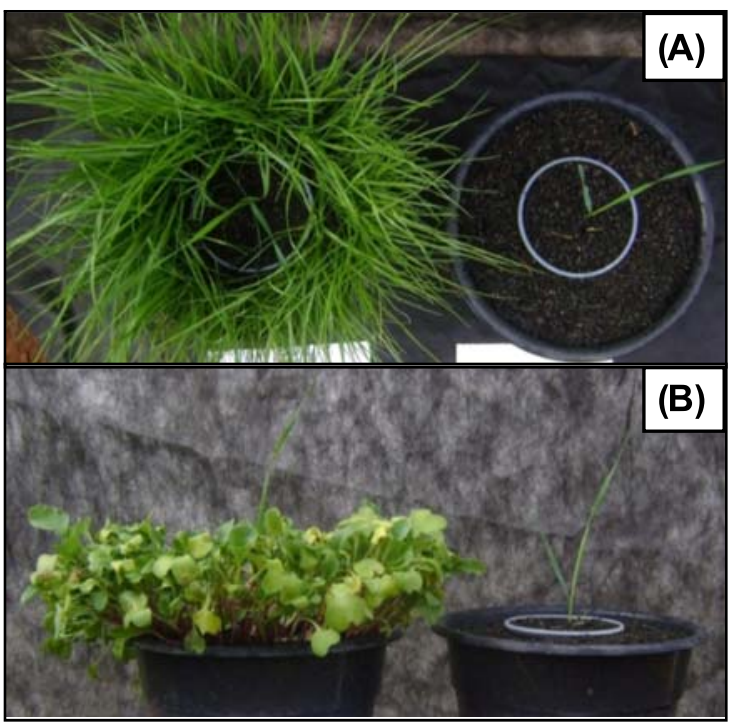

Figura 1 - Modelo de condução do experimento de competição inicial por radiação luminosa, 15 dias após a semeadura. (A) trigo (cv. Fundacep Cristalino) com azevém como planta competidora (esquerda) e testemunha (direita); (B) trigo (cv. Fundacep Cristalino) com nabo como planta competidora (esquerda) e testemunha (direita). UFSM, Campus Frederico Westphalen-RS, 2013.

Levene e Brown-Forsythe; havendo necessidade, foram realizadas transformações dos dados. Na sequência, os dados foram submetidos à análise de variância pelo teste $\mathrm{F}$ e, no caso de significância estatística, foram comparados pelo teste de Duncan a $5 \%$ de probabilidade do erro.

\section{RESULTADOS E DISCUSSÃO}

\section{Experimento I - Competição do trigo (cv. Fundacep Cristalino) com azevém, nabo e trigo (cv. BRS Guamirim)}

A estatura de planta do trigo foi $36 \%$ maior quando cultivado em competição com o azevém (Tabela 2). Quando o trigo conviveu com o nabo e com o trigo (cv. BRS Guamirim) como simulador de planta concorrente, não foi constatada diferença em relação à testemunha e à competição com o azevém (Tabela 2).

Para o tratamento livre de competição inicial por radiação luminosa, o comprimento de raizes foi estatisticamente maior $(35,97 \mathrm{~cm})$; quando o trigo cv. Fundacep Cristalino permaneceu sob competição inicial com trigo simulador de planta concorrente, o comprimento de raízes foi reduzido cerca de
$28 \%$ em relação ao tratamento livre de competição. Nos tratamentos em que Fundacep Cristalino cresceu na presença de plantas de nabo e azevém, o comprimento do sistema radicular equivaleu a 32,67 e $30,10 \mathrm{~cm}$, respectivamente (Tabela 2 ).

Quando comparada a relação entre o comprimento da parte aérea (estatura) e o comprimento do sistema radicular, observouse que Fundacep Cristalino teve menor relação quando foi isenta da competição inicial com "vizinhos" $(0,46)$. Por outro lado, os maiores valores foram obtidos quando o cultivar foi mantido em competição inicial com plantas de trigo simulador de planta concorrente $(0,72)$ e de azevém $(0,71)$ (Tabela 2).

Quando o trigo cv. Fundacep Cristalino permaneceu sob interferência de plantas competidoras por um periodo de 15 DAS, independentemente da espécie, houve alterações significativas quanto ao crescimento da parte aérea e comprimento do sistema radicular. Esses resultados corroboram os de Vidal \& Merotto Jr. (2010), os quais afirmam que as plantas são capazes de "perceber" a presença de plantas vizinhas em sua fase inicial de desenvolvimento e redirecionar o fluxo de fotoassimilados em função da qualidade de radiação luminosa interceptada pelas plântulas. O incremento na

Tabela 2 - Estatura de planta, comprimento de raízes e relação parte aérea e sistema radicular de trigo (cv. Fundacep Cristalino) sob competição com plantas de azevém, nabo, trigo (cv. BRS Guamirim) ou ausência de competição até 15 dias após a semeadura (DAS). UFSM, Campus Frederico Westphalen-RS, 2013

\begin{tabular}{|l|c|c|c|}
\hline \multicolumn{1}{|c|}{ Competição } & $\begin{array}{c}\text { Estatura } \\
(\mathrm{cm})\end{array}$ & $\begin{array}{c}\text { Comprimento } \\
\text { de raízes } \\
(\mathrm{cm})\end{array}$ & $\begin{array}{c}\text { Relação parte } \\
\text { aérea/sistema } \\
\text { radicular }\end{array}$ \\
\hline Azevém & $21,38 \mathrm{a}^{1 /}$ & $30,10 \mathrm{bc}$ & $0,71 \mathrm{a}$ \\
\hline Nabo & $18,13 \mathrm{ab}$ & $32,67 \mathrm{ab}$ & $0,58 \mathrm{~b}$ \\
\hline Trigo & $18,43 \mathrm{ab}$ & $26,00 \mathrm{c}$ & $0,72 \mathrm{a}$ \\
\hline Sem competição & $15,68 \mathrm{~b}$ & $35,97 \mathrm{a}$ & $0,46 \mathrm{c}$ \\
\hline Média & 18,40 & 31,10 & 0,63 \\
\hline CV $(\%)^{\underline{2} /}$ & 5,05 & 7,98 & 10,03 \\
\hline
\end{tabular}

${ }^{1 /}$ Médias seguidas por mesma letra não diferem entre si pelo teste de Duncan a 5\% de probabilidade de erro. ${ }^{2 /}$ Coeficiente de variação. 
estatura de plantas é atribuído como mecanismo de "fuga" da cultura da condição de baixa qualidade luminosa (Merotto Jr. et al., 2002), conforme se observou quando o trigo cresceu na presença de "vizinhos" como azevém, nabo ou trigo como simulador de planta competidora (cv. BRS Guamirim).

Os estímulos desencadeados nas plantas a fim de evitar um futuro sombreamento fazem com que o crescimento delas passe a ser continuamente ajustado, prevenindo estresses que possam vir a ser causados pela competição (Merotto Jr. et al., 2009). Quando há alterações na dinâmica de crescimento das plantas em detrimento da competição por radiação luminosa gerada pela baixa qualidade da luminosidade interceptada, alterações na dominância apical ocorrem. Quando essas alterações ocorrem na fase de estabelecimento das plantas, afetam precocemente o desenvolvimento de órgãos laterais (Zanine \& Santos, 2004), como número de afilhos em trigo (Valério et al., 2009). Do mesmo modo, foram observadas alterações morfológicas nas plantas de trigo, cv. Fundacep Cristalino, quando crescidas na presença de "vizinhos".

A reduzida capacidade de competição por radiação luminosa das culturas com plantas daninhas pode estar intimamente relacionada com a reduzida plasticidade fotomorfogênica das culturas, e os efeitos são agravados quando ambas as espécies apresentarem semelhança fisiológica e morfológica (Ballaré \& Casal, 2000). Desta forma, acredita-se ainda que, quanto mais próximas fisiologicamente as plantas, maior seja a interferência negativa ou competição entre elas. Isso foi evidente para Fundacep Cristalino, que sofreu maiores danos quando em interação com azevém ou plantas simuladoras de competição de trigo, cv. BRS Guamirim.

A presença de plantas competidoras não alterou o diâmetro de caule e o número de raízes do cultivar de trigo Fundacep Cristalino (dados não apresentados). Apesar das diferenças significativas entre os tratamentos observadas para a estatura no presente estudo (Tabela 2), o acúmulo de MSPA não foi afetado (Tabela 3). Por outro lado, constatou-se que, quando livre de competição inicial, houve maior acúmulo de MSSR (27,30 mg por planta), sendo estatisticamente superior aos demais. O menor acúmulo de MSSR (16,27 mg por planta) foi observado quando o trigo cresceu na presença de planta de trigo simuladora de planta concorrente. Para azevém $(26,08 \mathrm{mg}$ por planta) e nabo (19,98 mg por planta), observouse desempenho intermediário, porém sem diferir estatisticamente entre si e dos tratamentos superior e inferior, respectivamente (Tabela 3).

A relação entre o acúmulo de MSPA e o acúmulo de MSSR foi maior quando Fundacep Cristalino cresceu na presença de plantas de trigo cv. BRS Guamirim. Comportamento intermediário foi observado quando o trigo competiu com o nabo, sem, no entanto, diferir do tratamento superior. Quando livre de competição, também assumiu desempenho intermediário, sem diferir da presença de nabo e de azevém, com a menor relação MSPA/ MSSR (Tabela 3).

Tabela 3 - Massa seca de parte aérea (MSPA), massa seca de sistema radicular (MSSR) e relação MSPA e MSSR de trigo (cv. Fundacep Cristalino) sob competição com plantas de azevém, nabo, trigo (cv. BRS Guamirim) ou ausência de competição até 15 dias após a semeadura (DAS). UFSM, Campus Frederico Westphalen-RS, 2013

\begin{tabular}{|l|c|c|c|}
\hline \multicolumn{1}{|c|}{ Competição } & $\begin{array}{c}\text { MSPA } \\
\left(\mathrm{mg}^{\prime} \text { por planta) }\right.\end{array}$ & $\begin{array}{c}\text { MSSR } \\
(\mathrm{mg} \text { por planta) }\end{array}$ & Relação MSPA/MSSR \\
\hline Azevém & $27,58^{\mathrm{ns}}$ & $26,08 \mathrm{ab}^{1 /}$ & $0,93 \mathrm{c}$ \\
\hline Nabo & 26,53 & $19,98 \mathrm{bc}$ & $1,36 \mathrm{ab}$ \\
\hline Trigo & 21,83 & $16,27 \mathrm{c}$ & $1,43 \mathrm{a}$ \\
\hline Sem competição & 27,40 & $27,30 \mathrm{a}$ & $1,01 \mathrm{bc}$ \\
\hline Média & 26,01 & 22,49 & 1,18 \\
\hline $\mathrm{CV}(\%)^{2 /-}$ & 8,90 & 18,17 & 16,90 \\
\hline
\end{tabular}

${ }^{n s}$ Não significativo pelo teste de Duncan a 5\% de probabilidade de erro. 1/ Médias seguidas por mesma letra não diferem entre si pelo teste de Duncan a 5\% de probabilidade de erro..2/ Coeficiente de variação. 
Plantas de milho mantidas sob competição por radiação luminosa com plantas de Lolium perenne apresentaram menor abertura estomática, quando comparadas com aquelas mantidas livres da competição (Afifi \& Swanton, 2012). Como consequência do estresse ocorrido, houve aumento na concentração de $\mathrm{H}_{2} \mathrm{O}_{2}$ em nível celular, afetando a dinâmica de $\mathrm{K}^{+}$e do potencial osmótico das células-guarda, favorecendo o fechamento dos estômatos. Portanto, a redução da radiação luminosa incidente estimula o fechamento dos estômatos (Taiz \& Zeiger, 2004) e, com isso, ocorre redução na taxa fotossintética da planta e menor acúmulo de massa seca. No presente trabalho, isso foi constatado para a MSSR, não sendo observado para a MSPA.

\section{Experimento II - Competição do azevém com trigo (cv. Fundacep Cristalino) e nabo}

O efeito da competição inicial por radiação luminosa causada por plantas de trigo (cv. Fundacep Cristalino) e de nabo resultou em aumento significativo da estatura do azevém, comparativamente a quando este foi mantido livre da competição inicial (Tabela 4). Na ausência de interferência inicial, o comprimento de raiz $(18,58 \mathrm{~cm})$ foi maior, ao passo que na condição de competição com trigo ele foi reduzido em torno de $19 \%$. Na presença de nabo, o comprimento de raízes do azevém apresentou valor intermediário (Tabela 4).

Tabela 4 - Estatura de planta, comprimento de raízes e relação parte aérea e sistema radicular de azevém sob competição com plantas de trigo (cv. Fundacep Cristalino), nabo ou ausência de competição até 15 dias após a semeadura (DAS). UFSM, Campus Frederico Westphalen-RS, 2013

\begin{tabular}{|l|c|c|c|}
\hline \multicolumn{1}{|c|}{ Competição } & $\begin{array}{c}\text { Estatura } \\
(\mathrm{cm})\end{array}$ & $\begin{array}{c}\text { Comprimento } \\
\text { de raízes } \\
(\mathrm{cm})\end{array}$ & $\begin{array}{c}\text { Relação parte } \\
\text { aérea/sistema } \\
\text { radicular }\end{array}$ \\
\hline Trigo & $10,58 \mathrm{a}^{\underline{1}}$ & $12,81 \mathrm{c}$ & $0,83 \mathrm{a}$ \\
\hline Nabo & $11,00 \mathrm{a}$ & $15,03 \mathrm{~b}$ & $0,71 \mathrm{~b}$ \\
\hline Sem competição & $8,00 \mathrm{~b}$ & $18,58 \mathrm{a}$ & $0,43 \mathrm{c}$ \\
\hline Média & 9,86 & 15,51 & 0,65 \\
\hline $\mathrm{CV}(\%)^{\frac{2 /}{}}$ & 7,83 & 6,99 & 4,93 \\
\hline
\end{tabular}

1/ Médias seguidas por mesma letra não diferem entre si pelo teste de Duncan a 5\% de probabilidade de erro. ${ }^{2 /}$ Coeficiente de variação.
Sob interferência do cultivar de trigo Fundacep Cristalino, o azevém apresentou a maior relação entre o comprimento da parte aérea e o do sistema radicular. Por sua vez, o tratamento livre da competição apresentou a menor relação; quando crescido na presença de plantas de nabo, a relação foi intermediária (Tabela 4).

Quando as plantas recebem estímulos oriundos da competição inicial por radiação luminosa, há um dispêndio energético desregulado, o que pode comprometer o desenvolvimento das plantas em desvantagem (Rajcan \& Swanton, 2001). Plantas livres de competição investem boa parte dos fotoassimilados no desenvolvimento radicular, porém, quando em condição de competição por radiação luminosa, a planta passa a redirecionar a maior parte dos fotoassimilados para o crescimento da parte aérea. Desse modo, o azevém direcionou maior investimento para o crescimento em estatura em equilíbrio com o comprimento de raízes quando na presença de competidores, diferentemente de quando esteve sozinho, momento em que apresentou maior comprimento radicular do que da parte aérea.

O diâmetro de caule do azevém não mostrou diferença significativa, independentemente da presença de plantas competidoras ou sem o efeito de competição (dados não apresentados). Quanto ao número de raízes do azevém, quando este permaneceu sem a interferência ou sob interferência do nabo, eles não diferiram entre si, apresentando em média 3,50 e 3,00 raízes, respectivamente. No entanto, quando mantido sob interferência de Fundacep Cristalino, houve redução significativa do número de raízes, tendo-se observado, em média, 1,50 raiz por planta de azevém (Tabela 5).

Na Tabela 5 são observadas alterações significativas no número de raízes para o azevém quando este foi cultivado na presença de Fundacep Cristalino. Esse comportamento é observado quando a qualidade da radiação luminosa interceptada pelas plantas é afetada; de acordo com Afifi \& Swanton (2011), nessas condições, há alterações em nivel de sistema radicular, podendo este sofrer alterações funcionais, a ponto de afetar a sua longevidade e a habilidade da plântula em explorar o solo e captar água e nutrientes. 
Tabela 5 - Número de raízes, massa seca de parte aérea (MSPA), massa seca de sistema radicular (MSSR) e relação MSPA e MSSR de azevém sob competição com plantas de trigo (cv. Fundacep Cristalino), nabo ou ausência de competição até 15 dias após a semeadura (DAS). UFSM, Campus Frederico Westphalen-RS, 2013

\begin{tabular}{|l|c|c|c|c|}
\hline \multicolumn{1}{|c|}{ Competição } & Número de raízes & $\begin{array}{c}\text { MSPA } \\
(m g \text { por planta) }\end{array}$ & $\begin{array}{c}\text { MSSR } \\
\text { (mg por planta) }\end{array}$ & Relação MSPA/MSSR \\
\hline Trigo & $1,50 \mathrm{~b}^{\underline{\underline{1}}}$ & $2,17 \mathrm{~b}^{\underline{1} /}$ & $1,30 \mathrm{~b}$ & $1,85 \mathrm{a}$ \\
\hline Nabo & $3,00 \mathrm{a}$ & $4,08 \mathrm{a}$ & $3,65 \mathrm{a}$ & $1,17 \mathrm{~b}$ \\
\hline Sem competição & $3,50 \mathrm{a}$ & $1,50 \mathrm{c}$ & $0,99 \mathrm{~b}$ & $1,53 \mathrm{ab}$ \\
\hline Média & 2,67 & 2,62 & 2,04 & 1,49 \\
\hline CV $(\%)^{\underline{2} /}$ & 25,00 & 11,25 & 16,22 & 36,15 \\
\hline
\end{tabular}

1 Médias seguidas por mesma letra não diferem entre si pelo teste de Duncan a 5\% de probabilidade de erro. ${ }^{2} /$ Coeficiente de variação.

Quando o azevém foi mantido sob competição inicial com nabo, foi observado incremento aproximado de $172 \%$ de MSPA quando comparado à testemunha sem competidores (Tabela 5). Quando o azevém competiu com trigo, o acúmulo de MSPA foi $45 \%$ superior ao da testemunha.

Para a variável MSSR, assim como para MSPA, o maior acúmulo foi observado quando o azevém conviveu com nabo (Tabela 5). No momento em que o azevém permaneceu livre da competição inicial, o acúmulo de MSSR não diferiu do acumulado quando em convivência inicial com plantas de trigo cv. Fundacep Cristalino (Tabela 5).

A maior relação entre o acúmulo de MSPA e o acúmulo de MSSR foi observada quando o azevém conviveu na fase inicial com plantas de trigo cv. Fundacep Cristalino $(1,85)$, sem diferir, no entanto, do tratamento em que permaneceu livre da competição inicial $(1,53)$, que representa o tratamento com desempenho intermediário. A menor relação entre os acúmulos de MSPA e MSSR foi observada quando o azevém foi mantido em interação com plantas de nabo em sua fase inicial de desenvolvimento, porém sem diferir do tratamento intermediário (Tabela 5).

Os maiores acúmulos de MSPA e de MSSR em condição de competição ou presença de competidores pode ser um indicativo de que o azevém apresenta alguma vantagem adaptativa. Para Castro \& Garcia (1996), quando uma planta se encontra em situação de competição e consegue, mesmo assim, assimilar $\mathrm{CO}_{2}$ e utilizá-lo no processo de fotossintese e aumentar sua área foliar e estatura, alterando suas características de acordo com as condições encontradas no ambiente, esse genótipo possui grande vantagem adaptativa, por apresentar plasticidade.

\section{Experimento III - Competição do nabo com azevém e trigo (cv. Fundacep Cristalino)}

A estatura de planta do nabo foi reduzida quando cultivado na condição sem competição até 15 DAS $(1,93 \mathrm{~cm})$, sendo estatisticamente inferior à dos demais (Tabela 6); ela foi maior quando em convivência com plantas de Fundacep Cristalino (5,90 cm). Já para o comprimento de raízes, o menor valor foi observado quando o nabo esteve na presença do trigo $(13,10 \mathrm{~cm})$, cerca de $14,83 \mathrm{~cm}$ inferior à média dos tratamentos em que o nabo conviveu com azevém $(26,33 \mathrm{~cm})$, e na condição sem competição $(29,53 \mathrm{~cm})$, não diferindo estatisticamente entre si (Tabela 6).

Tabela 6 - Estatura de planta, comprimento de raízes e relação parte aérea e sistema radicular de nabo sob competição com plantas de trigo (cv. Fundacep Cristalino), azevém ou ausência de competição até os 15 dias após a semeadura (DAS). UFSM, Campus Frederico Westphalen-RS, 2013

\begin{tabular}{|l|c|c|c|}
\hline \multicolumn{1}{|c|}{ Competição } & $\begin{array}{c}\text { Estatura } \\
(\mathrm{cm})\end{array}$ & $\begin{array}{c}\text { Comprimento } \\
\text { de raízes } \\
(\mathrm{cm})\end{array}$ & $\begin{array}{c}\text { Relação parte } \\
\text { aérea/sistema } \\
\text { radicular }\end{array}$ \\
\hline Trigo & $5,90 \mathrm{a}^{\underline{1}}$ & $13,10 \mathrm{~b}$ & $0,45 \mathrm{a}$ \\
\hline Azevém & $4,18 \mathrm{~b}$ & $26,33 \mathrm{a}$ & $0,19 \mathrm{~b}$ \\
\hline Sem competição & $1,93 \mathrm{c}$ & $29,53 \mathrm{a}$ & $0,07 \mathrm{c}$ \\
\hline Média & 3,83 & 23,64 & 0,22 \\
\hline $\mathrm{CV}(\%)^{\underline{2} /}$ & 11,81 & 6,53 & 18,27 \\
\hline
\end{tabular}

1/ Médias seguidas por mesma letra não diferem entre si pelo teste de Duncan a 5\% de probabilidade de erro. 느 Coeficiente de variação.

Planta Daninha, Viçosa-MG, v. 33, n. 1, p. 13-22, 2015 
Quando o nabo foi mantido sem competição, apresentou relação entre parte aérea e sistema radicular de 0,07 , consistindo na menor relação (Tabela 6). Por outro lado, quando mantido sob interferência de Fundacep Cristalino, ele apresentou relação equivalente a 0,45 , estatisticamente superior à dos demais.

Para a variável diâmetro de caule, o nabo apresentou diferenças significativas (Tabela 7), o que não pôde ser observado para o cultivar de trigo Fundacep Cristalino e para o azevém (dados não apresentados), que se mostraram indiferentes à competição para essa característica. Quando o nabo foi mantido livre da presença de competidores ou em interação com plantas de azevém, o diâmetro do caule foi estatisticamente superior ao diâmetro observado para a condição em que o nabo permaneceu com plantas de trigo cv. Fundacep Cristalino (Tabela 7).

Quanto à variável MSPA, o maior acúmulo para o nabo foi verificado quando este foi mantido sob interação inicial com o azevém (67,48 $\mathrm{mg}$ por planta), sendo este tratamento estatisticamente superior à condição livre de interferência $(41,30 \mathrm{mg}$ por planta) e sob interferência do cultivar de trigo Fundacep Cristalino (31,87 mg por planta) (Tabela 7). O maior acúmulo de MSSR foi observado quando o nabo foi mantido sem competição inicial por radiação luminosa (14,00 $\mathrm{mg}$ por planta): cerca de 88 e $51 \%$ a mais que a MSSR quando na presença de trigo e de azevém, respectivamente (Tabela 7).

No tocante à relação entre a MSPA e a MSSR, ela foi superior quando o nabo competiu com o azevém $(7,01)$. A menor relação entre as variáveis foi quando o nabo permaneceu sem competição $(2,99)$, sendo este estatisticamente inferior aos demais tratamentos (Tabela 7).

Quando as plantas são expostas às condições que predizem a competição por radiação luminosa, o padrão da distribuição de fotoassimilados é alterado antes mesmo que a taxa de fotossintese seja reduzida efetivamente pelo sombreamento (Ballaré \& Casal, 2000). Isso pode ser entendido como uma estratégia de busca por uma condição de interceptação luminosa direta e de se antecipar à condição de competição extrema pelo recurso luminoso. Embora o crescimento do caule e o acúmulo de matéria seca possam ser correlacionados, as alterações na distribuição da matéria seca não são simples resultado do alongamento do caule, mas possivelmente incluem alterações na fixação de carbono (Ballaré \& Casal, 2000).

Estudos que abordam a competição por radiação luminosa entre plantas daninhas e cultivadas vêm sendo realizados há tempos (Stoller \& Woolley, 1985). Ballaré et al. (1987) investigaram a detecção precoce de plantas vizinhas através da percepção pelo fitocromo, por meio de mudanças espectrais da radiação solar refletida, e inferiram que a habilidade de uma planta identificar sua posição relativa em uma população pode ser fator determinante no sucesso de sua perpetuação. A adaptação das plantas às alterações da qualidade de radiação solar está relacionada a presença do fitocromo, uma vez que, por se tratar de um pigmento reversivel em resposta à radiação vermelho:vermelho distante,

Tabela 7 - Diâmetro do caule, massa seca de parte aérea (MSPA), massa seca de sistema radicular (MSSR) e relação MSPA e MSSR de nabo sob competição com plantas de trigo (cv. Fundacep Cristalino), azevém ou ausência de competição até 15 dias após a semeadura (DAS). UFSM, Campus Frederico Westphalen-RS, 2013

\begin{tabular}{|l|c|c|c|c|}
\hline \multicolumn{1}{|c|}{ Competição } & $\begin{array}{c}\text { Diâmetro do caule } \\
(\mathrm{mm})\end{array}$ & $\begin{array}{c}\text { MSPA } \\
(\mathrm{mg} \text { por planta })\end{array}$ & $\begin{array}{c}\text { MSSR } \\
(\mathrm{mg} \text { por planta) }\end{array}$ & MSPA/MSSR \\
\hline Trigo & $15,00 \mathrm{~b}^{1 /}$ & $31,87 \mathrm{~b}$ & $7,43 \mathrm{~b}$ & $4,23 \mathrm{~b}$ \\
\hline Azevém & $20,25 \mathrm{a}$ & $67,48 \mathrm{a}$ & $9,27 \mathrm{~b}$ & $7,01 \mathrm{a}$ \\
\hline Sem competição & $21,75 \mathrm{a}$ & $41,30 \mathrm{~b}$ & $14,00 \mathrm{a}$ & $2,99 \mathrm{c}$ \\
\hline Média & 19,36 & 48,94 & 9,95 & 4,76 \\
\hline CV $(\%)^{2 / /}$ & 7,64 & 5,29 & 8,23 & 10,36 \\
\hline
\end{tabular}

1/ Médias seguidas por mesma letra não diferem entre si pelo teste de Duncan a $5 \%$ de probabilidade de erro. ${ }^{2}$ Coeficiente de variação. 
infere-se que esse tipo de comprimento de ondas seja a base para informações que auxiliam a planta a se ajustar às novas condições ambientais em que ela esteja inserida (Taiz \& Zeiger, 2004). A percepção precoce de vizinhos por plantas cultivadas, como o trigo, pode desencadear alterações morfológicas, mas que somente serão comprometedoras se não forem compensadas e virem a causar penalidade na produtividade de grãos. O presente estudo mostra que a percepção desencadeia alterações diferenciadas, conforme a espécie competidora "vizinha".

Em função da qualidade da luz que uma plântula recebe logo no início do seu desenvolvimento, ela é capaz de regular a distribuição de fotossintatos e de alterar seu crescimento. Assim, a capacidade das plantas de detectar a qualidade da luz começa ainda muito cedo, e essa é a primeira forma de interferência negativa entre plantas (Vidal et al., 2012). No presente estudo, plantas de trigo, azevém e nabo foram capazes de perceber a presença de "plantas vizinhas competidoras" em estádios iniciais de desenvolvimento, alterando características morfológicas, como o aumento da estatura de planta em detrimento do comprimento radicular. Desse modo, a convivência inicial do trigo cv. Fundacep Cristalino é mais afetada pela presença de plantas de trigo cv. BRS Guamirim como simuladora de planta concorrente, com redução do desenvolvimento radicular. Essas informações reforçam a importância do estabelecimento da lavoura no limpo, evitando alterações na estrutura da planta cultivada, sendo estas mais pronunciadas quanto mais semelhantes forem as espécies em convivência. Estudos posteriores poderão ser conduzidos visando investigar se as alterações iniciais em consequência da convivência inicial se mantêm e, desse modo, alteram as relações de competição entre a planta competidora e a planta cultivada, podendo comprometer a produtividade de grãos.

\section{AGRADECIMENTOS}

Ao Pesquisador Mario A. Bianchi da CCGL Tec, bem como à Embrapa Trigo, pela disponibilização das sementes de trigo utilizadas nos estudos; à Capes, ao CNPq e à Fapergs, pela concessão de bolsas de iniciação científica e de mestrado (PPGAAA/UFSM).

\section{LITERATURA CITADA}

AFIFI, M.; SWANTON, C. Maize seed and stem roots differ in response to neighbouring weeds. Weed Res., v. 51, n. 5, p. 442-450, 2011.

AFIFI, M.; SWANTON, C. Early physiological mechanisms of weed competition. Weed Sci., v. 60, n. 4, p. 542-551, 2012.

ALMEIDA, M. L.; MUNDSTOCK, C. M. A qualidade da luz afeta o afilhamento em plantas de trigo, quando cultivadas sob competição. Ci. Rural, v. 31, n. 3, p. 401-408, 2001.

BALLARÉ, C. L.; CASAL, J. J. Light signals perceived by crop and weed plants. Field Crops Res., v. 67, n. 2, p. 149-160, 2000.

BALLARÉ, C. L. et al. Early detection of neighbor plants by phytochrome perception of spectral changes in reflected sunlight. Plant Cell Environ., v. 10, n. 7, p. 551-557, 1987.

BALLARÉ, C. L.; SCOPEL, A. L.; SÁNCHEZ, R. A. Far-red radiation reflected from adjacent leaves: an early signal of competition in plant canopies. Science, v. 247, n. 4940, p. 329-332, 1990.

CASTRO, C. R. T.; GARCIA, R. Competição entre plantas com ênfase no recurso luz. Ci. Rural, v. 26, n. 1, p. 167-174, 1996.

MEROTTO Jr., A.; FISCHER, A. J.; VIDAL, R. A. Perspectives for using light quality knowledge as an advanced ecophysiological weed management tool. Planta Daninha, v. 27, n. 2, p. 407-419, 2009.

MEROTTO Jr., A. et al. Interferência das plantas daninhas sobre o desenvolvimento inicial de plantas de soja e arroz através da qualidade da luz. Planta Daninha, v. 20, n. 1, p. 9-16, 2002.

RAJCAN, I.; SWANTON, C. L. Red-far-red ratio of reflected light: a hypothesis of why early-season weed control is important in corn. Weed Sci., v. 52, n. 5, p. 774-778, 2004.

RAJCAN, I.; SWANTON, C. L. Understanding maize-weed competition: resource competition, light quality and the whole plant. Field Crop Res., v. 71, n. 2, p. 139-150, 2001.

STOLLER, E. W.; WOOLLEY, J. T. Competition for light by broadleaf weeds in soybeans (Glycine max). Weed Sci., v. 33, n. 2, p. 199-202, 1985.

TAIZ, L.; ZEIGER, E. Respostas à luz: movimentos estomáticos e morfogênese. In: TAIZ, L.; ZEIGER, E. Fisiologia vegetal. Porto Alegre: Artmed, 2004. p. 505-526. 
VALÉRIO, I. P. et al. Fatores relacionados à produção e desenvolvimento de afilhos em trigo. Semina: Ci. Agr., v. 30, n. 1, p. 1207-1218, 2009.

VIDAL, R. A. et al. Initialism as a mechanism of weed interference: can a crop plant be blinded? Planta Daninha, v. 30, n. 3, p. 469-475, 2012.
VIDAL, R. A.; MEROTTO Jr., A. Inicialismo. In: VIDAL, R. (Ed). Interação negativa entre plantas: inicialismo, alelopatia e competição. Porto Alegre: Evangraf, 2010. p. 33-49.

ZANINE, A. M.; SANTOS, E. M. Competição entre espécies de plantas - uma revisão. R. FZVA, v. 11, n. 1, p. 10-30, 2004. 